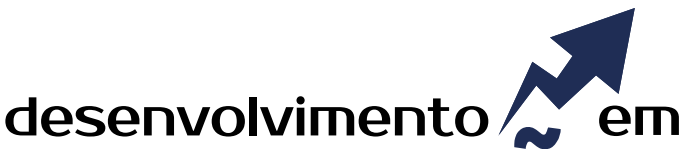 QUESTÃO
}

\section{Análise dos Níveis de Participação Institucional e de Gestão Social no Território da Cidadania Noroeste Colonial RS}

http://dx.doi.org/10.21527/2237-6453.2019.46.181-198

Recebido em: $12 / 4 / 2017$

Aceito em: 4/9/2018

\author{
Nilson Luiz Costa, ${ }^{1}$ Antônio Joreci Flores, ${ }^{2}$ Viviane Ottonelli Costa, ${ }^{3}$ \\ Elaine Marisa Andriolli, ${ }^{4}$ Antônio Cordeiro de Santana ${ }^{5}$
}

\begin{abstract}
RESUMO
O objetivo do presente artigo foi caracterizar a socioeconomia do Território da Cidadania Noroeste Colonial RS e avaliar os níveis de participação institucional e de gestão social no âmbito das relações entre o Colegiado de Desenvolvimento Territorial e as instituições. Pretendeu-se, com isso, identificar se os atores estão aptos a liderar o processo de planejamento do desenvolvimento territorial. A caracterização socioeconômica foi realizada por meio da estatística descritiva e análise gráfica e os níveis de participação institucional e gestão social foram aferidos mediante a Análise Fatorial Exploratória. Um componente fundamental da pesquisa, com enfoque de cidadania, foi a busca por informações e diálogo com a sociedade política e a sociedade civil, bem como o seu entendimento e envolvimento com a política de desenvolvimento territorial e desenvolvimento sustentável. A pesquisa foi realizada em 21 dos 34 municípios do Território em questão e teve como público participante 116 pessoas integrantes de entidades como os Conselhos Municipais de Desenvolvimento - Comudes - entidade composta por agentes públicos - e instituições e pessoas da sociedade civil de cada município. Entre os principais resultados destacam-se a existência de assimetrias socioeconômicas entre os municípios do território e o surgimento de um elevado nível de consciência e engajamento em torno da política de desenvolvimento territorial.
\end{abstract}

Palavras-chave: Desenvolvimento territorial. Capital social. Arranjo institucional.

\section{INSTITUTIONAL PARTICIPATION AND SOCIAL MANAGEMENT IN THE TERRITORY OF NORTHWEST COLONIAL CITIZENSHIP RS}

\begin{abstract}
The objective of this article was to characterize the socioeconomics of the Território da Cidadania Noroeste Colonial from Rio Grande do Sul State - Brazil and to evaluate the levels of institutional participation and social management in the scope of the relations between institutions in the Colegiado de Desenvolvimento Territorial. It was intended, therefore, to identify if the actors are able to lead the process of territorial development planning. Socioeconomic characterization was performed through descriptive statistics and graphical analysis and the levels of institutional participation and social management were measured through the Exploratory Factor Analysis. A fundamental component of the research, with a focus on citizenship, was the search for information and dialogue with political society and civil society, as well as their understanding and involvement with the territorial development and sustainable development policy. The survey was carried out in 21 of the 34 municipalities of the Territory in question. As a participating public, 116 people were members of entities such as the Municipal Development Councils (Comudes), which is composed of both public officials and entities and Civil society in each municipality. Among the main results, we highlight the existence of socioeconomic asymmetries between the municipalities of the territory and the emergence of a high level of awareness and engagement around territorial development policy.
\end{abstract}

Keywords: Territorial development. Social capital. Institutional arrangement.

\footnotetext{
${ }^{1}$ Doutor em Ciências Agrárias pela Universidade Federal Rural da Amazônia (Ufra). Professor da Universidade Federal de Santa Maria (UFSM), campus Palmeira das Missões. nilson.costa@ufsm.br

2 Doutor em Desenvolvimento Regional pela Universidade de Santa Cruz do Sul (Unisc). Professor da Universidade Federal de Santa Maria (UFSM), campus Palmeira das Missões. a1flores@terra.com.br

3 Mestre em Educação pela Universidade Estadual do Pará (Uepa). Bolsista do Núcleo de Extensão em Desenvolvimento Territorial no Território da Cidadania Noroeste Colonial/RS (USM). viviottonelli@hotmail.com

${ }^{4}$ Aluna do Mestrado em Desenvolvimento Rural pela Universidade Federal do Rio Grande do Sul. elainemarisa@hotmail.com

${ }^{5}$ Doutor em Economia Aplicada pela Universidade Federal de Viçosa (UFV). Professor da Universidade Federal Rural da Amazônia (Ufra). acsufra@gmail.com
} 
O desenvolvimento territorial tem sido largamente discutido nas diversas instâncias, principalmente num contexto amplo, em que várias contribuições passam a tentar orientar um processo que consiga proporcionar maior eficiência nas atividades produtivas do país, Estados e municípios. Nessa perspectiva, a partir do desenvolvimento com maior participação da sociedade, o país passou, a partir de 2003, a adotar a proposição do desenvolvimento territorial com a conotação mais focada no rural, propondo então a organização do Planos Territoriais de Desenvolvimento Rural - PTDRs elaborados de maneira participativa com os atores desse segmento. Já a partir do ano de 2008 a conotação do desenvolvimento territorial abarcou também as questões do espaço urbano, somando-se, então, ao espaço rural já em discussão.

Com efeito, surgiu o que se denomina Territórios da Cidadania, em que não se separa o rural do urbano, mas os une. A denominação cidadania surgiu a partir da identificação no Índice de Desenvolvimento Humano - IDH - dos baixos índices identificados para determinada região, o que deveria sinalizar maior apoio de políticas públicas para encaminhar soluções possíveis para a melhoria nos índices com problemas identificados.

Nesse sentido, é importante destacar as iniciativas da Secretaria de Desenvolvimento Territorial - SDT - integrante do Ministério do Desenvolvimento Agrário - MDA - visando a instituir o Programa de Desenvolvimento Regional, Territorial Sustentável e Economia Solidária, já com vários resultados importantes nas diversas regiões do Estado do Rio Grande do Sul, como é o caso da região Norte do Estado, na qual vários territórios, tanto rurais como da cidadania estão, uns em implantação e outros buscando sua consolidação.

Com o propósito de contribuir com a dinâmica da Política de Desenvolvimento Territorial, a Universidade Federal de Santa Maria, campus de Palmeira das Missões, propôs, no âmbito da chamada pública CNPq/MDA/SPM-PR no 11/2014, a criação de um Núcleo de Extensão em Desenvolvimento Territorial do Território da Cidadania Noroeste Colonial do Rio Grande do Sul (Nedet-Norc/RS).

Nesse contexto, o objetivo do trabalho foi caracterizar a socioeconomia do Território da Cidadania e analisar a participação institucional e gestão social no território, de modo a responder à seguinte questão norteadora: As institucionalidades presentes no Território da Cidadania Noroeste Colonial RS estão preparadas para liderar o processo de planejamento do desenvolvimento territorial?

A caracterização socioeconômica foi realizada por meio da estatística descritiva e análise gráfica e as dimensões configuradas pela participação institucional e a gestão social foram definidas mediante a Análise Fatorial Exploratória.

O texto está dividido em cinco seções, das quais esta é a primeira. Na segunda seção descreve-se o referencial teórico, enquanto que nas seções seguintes foram apresentados o desenvolvimento metodológico, resultados e discussões e as considerações finais.

\section{O CAPITAL SOCIAL E O PROCESSO DE DESENVOLVIMENTO TERRITORIAL}

Ao longo das últimas décadas as distintas escolas do pensamento econômico trouxeram contribuições que permitiram entender as dinâmicas que explicam os processos de crescimento e desenvolvimento econômico. Das análises de desenvolvimento eco- 
nômico derivaram conceitos como desenvolvimento regional, desenvolvimento rural, desenvolvimento territorial, entre outros. Cada um com a sua especificidade, mas todos com o princípio básico de não associar, necessariamente, o crescimento da riqueza com os níveis de bem-estar social.

Nesta perspectiva Abramovay $(1998,2000)$ destaca a importância da proximidade social e da coordenação entre os atores no processo de fomento ao empreendedorismo e inovação. Dada a importância das relações sociais, deduz o autor que uma das dimensões que condiciona o processo de desenvolvimento é a territorial, e outra, o capital social.

Para Putnam (2000, p. 177), "O capital social diz respeito a características da organização social, como confiança, normas e sistemas, que contribuam para aumentar a eficiência da sociedade, facilitando as ações coordenadas". A importância deste reside na possibilidade de reduzir os custos de transações e facilitar a cooperação espontânea, a partir de regras de reciprocidade e sistemas de participação cívica, de modo que, na presença de capital social, os dilemas da ação coletiva tendem a ser facilmente superados.

O capital social é, portanto, algo muito benéfico para a sociedade, mas suas características o tornam um bem público - a propriedade não pode ser atribuída a um particular e o uso por um indivíduo não afeta o uso por outro - e bens públicos tendem a ser suprimidos/subvalorizados pelos agentes. Em função disto, em um primeiro momento, é possível e provável o surgimento de um conjunto de dificuldades para a criação do capital social, especialmente geradas pelo comportamento oportunista (que busca o benefício da cooperação alheia sem nada oferecer em troca), mas segue concluindo que o próprio sistema comunitário tende a criar mecanismos de punição aos transgressores. Em última análise,

[...] quanto mais elevado o nível de confiança em uma comunidade, maior a probabilidade de haver cooperação. E a própria cooperação gera confiança. A progressiva acumulação de capital social é uma das principais responsáveis pelos círculos virtuosos da Itália cívica (PUTNAM, 2000, p. 180).

De fato, o capital social assume papel relevante e, conforme destaca Abramovay (2000, p. 4), "os indivíduos não agem independentemente, que seus objetivos não são estabelecidos de maneira isolada e seu comportamento nem sempre é estritamente egoísta". Em razão disso, a dimensão institucional passa a também explicar os níveis de desenvolvimento.

Para Stiglitz (1998), o capital social não é algo que possa ser ofertado ou dado de presente, não pode ser entregue, mas pode ser desenvolvido a partir de um processo endógeno, que está relacionado à capacidade de cada país. No mesmo sentido, Gordillo de Anda (1997) e Putnam (2000) ratificam o papel do capital social no processo de mudança e desenvolvimento local, internacional e institucional.

Dada a relevância do capital social, o presente estudo propõe-se a identificar a percepção dos agentes quanto às dinâmicas de cooperação e colaboração no Colegiado de Desenvolvimento Territorial do Território da Cidadania Noroeste Colonial RS (Codeter). 
Este colegiado, conforme destaca Deckert (2017), é composto por membros da sociedade civil e do poder público. Dessa forma,

o Codeter do Território Noroeste Colonial é integrado por 86 entidades, sendo 43 representantes da Sociedade Civil e as demais do Poder Público. O colegiado possui divisões diferentes, cada entidade tem um representante, os quais são divididos entre núcleo técnico e núcleo dirigente. Dentro do Codeter existem ainda seis setoriais, cada uma representada por cidadãos da comunidade, escolhidos para trazer os anseios do seu meio para dentro do colegiado. As setoriais são: povos indígenas, reforma agrária, educação, assistência social, agricultura familiar e saúde.

O objetivo do Codeter é criar condições que propiciem o desenvolvimento econômico e melhorem a qualidade de vida, principalmente das populações em situação de vulnerabilidade social. Ou seja, o desenvolvimento é um processo e não um produto (ABRAMOVAY, 2000). Dificilmente ele será alcançado por meio da ação externa, pelo contrário, deve ser planejado de forma endógena, de modo a orientar as políticas públicas e fortalecer as instituições.

Por ser um espaço caracterizado por coordenar a ação coletiva, a Secretaria de Desenvolvimento Territorial (SDT) do Ministério do Desenvolvimento Agrário (MDA) e a Secretaria de Políticas Públicas para Mulheres propuseram, em parceria com o ConseIho Nacional de Desenvolvimento Científico e Tecnológico (CNPq), a criação de Núcleos de Extensão em Desenvolvimento Territorial (Nedets). Nesse contexto, a Universidade Federal de Santa Maria, campus de Palmeira das Missões, foi contemplada com recursos para a instituição de um Núcleo de Extensão em Desenvolvimento Territorial do Território da Cidadania Noroeste Colonial do Rio Grande do Sul (Nedet-Norc/RS). Por fim, o objetivo do Nedet-Norc/RS foi prestar assessoria ao Codeter e qualificar as ações de modo a impulsionar atores regionais a terem um envolvimento mais consistente no efetivo planejamento das políticas públicas.

\section{DESENVOLVIMENTO METODOLÓGICO}

O trabalho pode ser caracterizado como de natureza exploratório-descritivo, quanto aos fins, e como pesquisa de campo quanto aos meios. Todos os dados receberam tratamento com técnicas de estatística descritiva e inferencial, cujos passos são descritos nos itens a seguir.

\section{Fonte de Dados}

Para caracterizar a socioeconomia do território foram utilizados dados socioeconômicos contidos no Atlas do Desenvolvimento Humano no Brasil (BRASIL, 2013).

Para estudar as dimensões relacionadas à participação institucional e gestão social, utilizaram-se dados primários, que foram obtidos mediante a aplicação de 116 questionários autoadministrados, fechados, com lideranças municipais participantes da sociedade civil e de instituições públicas que se relacionam, de alguma forma, com o Colegiado de Desenvolvimento Territorial. 
A amostra foi definida por conveniência e por julgamento, uma vez que não foi possível garantir a aleatoriedade da amostra, pois foram convidados a responder os questionários todos os presentes nas diversas reuniões realizadas entre a equipe do Núcleo de Extensão em Desenvolvimento Territorial do Território da Cidadania Noroeste Colonial, com a presença de integrantes de Conselhos Municipais de Desenvolvimento (Comudes), presidentes de Sindicatos, representantes de movimentos sociais, mulheres e jovens rurais, entre outros. As reuniões ocorreram nos municípios de ljuí, Braga, Campo Novo, Boa Vista do Cadeado, Miraguaí, Coronel Bicaco, Santo Augusto, Ajuricaba, Condor, Panambi, Augusto Pestana, Coronel Barros, Esperança do Sul, Tiradentes do Sul, Três Passos, Vista Gaúcha, São Valério do Sul, Santo Augusto e Chiapetta entre os meses de maio e junho de 2016.

Quadro 1 - Variáveis utilizadas nas análises e questões arguidas aos entrevistados

\begin{tabular}{|c|c|}
\hline Variável & Descrição da Variável \\
\hline $\begin{array}{l}\mathrm{X}_{1} \cdot \text { Minha instituição integra o } \\
\text { Codeter }\end{array}$ & $\begin{array}{l}\text { Corresponde à questão } 8.14 \text { do instrumento de coleta } \\
\text { de dados: Minha instituição integra o Colegiado de } \\
\text { Desenvolvimento Territorial (Codeter) }\end{array}$ \\
\hline $\begin{array}{l}\mathrm{X}_{2} \text {. Codeter é espaço para discutir } \\
\text { projetos estratégicos }\end{array}$ & $\begin{array}{l}\text { Corresponde à questão } 8.15 \text { do instrumento de coleta de } \\
\text { dados: O Colegiado de Desenvolvimento Territorial é um } \\
\text { espaço para discutir projetos estratégicos regionais }\end{array}$ \\
\hline $\begin{array}{l}\mathrm{X}_{3} \text {. Codeter sabe as metas que } \\
\text { deve alcançar }\end{array}$ & $\begin{array}{l}\text { Corresponde à questão } 8.17 \text { do instrumento de coleta } \\
\text { de dados: Sabemos claramente quais são nossas metas e } \\
\text { objetivos no Colegiado Territorial }\end{array}$ \\
\hline $\begin{array}{l}\mathrm{X}_{4} \cdot \text { Movimentos sociais possuem } \\
\text { atuação relevante no Codeter }\end{array}$ & $\begin{array}{l}\text { Corresponde à questão } 8.19 \text { do instrumento de coleta de } \\
\text { dados: os movimentos sociais possuem atuação relevante } \\
\text { no Colegiado }\end{array}$ \\
\hline $\begin{array}{l}\mathrm{X}_{5} . \text { Prefeituras possuem atuação } \\
\text { relevante no Codeter }\end{array}$ & $\begin{array}{l}\text { Corresponde à questão } 8.20 \text { do instrumento de coleta } \\
\text { de dados: as prefeituras possuem atuação relevante no } \\
\text { Colegiado }\end{array}$ \\
\hline $\begin{array}{l}\mathrm{X}_{6} \text {. Órgãos públicos possuem } \\
\text { atuação relevante no Codeter }\end{array}$ & $\begin{array}{l}\text { Corresponde à questão } 8.21 \text { do instrumento de coleta de } \\
\text { dados: outros órgãos públicos possuem atuação relevante } \\
\text { no Colegiado }\end{array}$ \\
\hline $\mathrm{X}_{7}$. Comudes é atuante & $\begin{array}{l}\text { Corresponde à questão } 8.3 \text { do instrumento de coleta de } \\
\text { dados: o Comudes de meu município é atuante e discute o } \\
\text { desenvolvimento municipal }\end{array}$ \\
\hline $\begin{array}{l}X_{8} \text {. Conselho de Desenvolvimento } \\
\text { Rural é atuante }\end{array}$ & $\begin{array}{l}\text { Corresponde à questão } 8.5 \text { do instrumento de coleta de } \\
\text { dados: o Conselho Municipal de Desenvolvimento Rural é } \\
\text { atuante e discute o desenvolvimento rural sustentável }\end{array}$ \\
\hline $\begin{array}{l}\mathrm{X} \cdot \text {. Projetos tramitados no } \\
\text { Território são discutidos }\end{array}$ & $\begin{array}{l}\text { Corresponde à questão } 9.1 \text { do instrumento de coleta de } \\
\text { dados: nós discutimos os projetos tramitados no território }\end{array}$ \\
\hline $\begin{array}{l}\mathrm{X}_{10} \cdot \text { A gestão social do território } \\
\text { favorece o desenvolvimento local }\end{array}$ & $\begin{array}{l}\text { Corresponde à questão } 9.12 \text { do instrumento de coleta de } \\
\text { dados: a gestão social das políticas territoriais contribui } \\
\text { para os processos de desenvolvimento local }\end{array}$ \\
\hline $\begin{array}{l}\mathrm{X}_{11} \text {. As mulheres participam das } \\
\text { discussões de desenvolvimento } \\
\text { rural }\end{array}$ & $\begin{array}{l}\text { Corresponde à questão } 9.13 \text { do instrumento de coleta de } \\
\text { dados: as mulheres participam ativamente das discussões } \\
\text { de desenvolvimento rural }\end{array}$ \\
\hline $\begin{array}{l}\mathrm{X}_{12} \cdot \text { os jovens participam das } \\
\text { discussões de desenvolvimento } \\
\text { territorial }\end{array}$ & $\begin{array}{l}\text { Corresponde à questão } 9.16 \text { do instrumento de coleta de } \\
\text { dados: os jovens participam ativamente das discussões de } \\
\text { desenvolvimento rural }\end{array}$ \\
\hline
\end{tabular}




\begin{tabular}{|l|l|}
\hline $\begin{array}{l}X_{13} \text {. No território, direitos e } \\
\text { deveres são iguais }\end{array}$ & $\begin{array}{l}\text { Corresponde à questão 9.2 do instrumento de coleta de } \\
\text { dados: no território, direitos e deveres são iguais para } \\
\text { todos }\end{array}$ \\
\hline $\begin{array}{l}X_{14} \text {. Existe cooperação nas pautas } \\
\text { do Codeter }\end{array}$ & $\begin{array}{l}\text { Corresponde à questão 9.5 do instrumento de coleta de } \\
\text { dados: as discussões e ações territoriais são caracterizadas } \\
\text { pela cooperação entre os participantes }\end{array}$ \\
\hline $\begin{array}{l}X_{15} \text {. O principal interesse dos } \\
\text { membros do Codeter é o } \\
\text { desenvolvimento da região }\end{array}$ & $\begin{array}{l}\text { Corresponde à questão 9.8 do instrumento de coleta de } \\
\text { dados: acredito que o principal interesse dos envolvidos } \\
\text { no território é o desenvolvimento de nossa região }\end{array}$ \\
\hline $\begin{array}{l}X_{16} \text { A união da sociedade } \\
\text { civil e órgãos governamentais } \\
\text { é importante para o } \\
\text { desenvolvimento }\end{array}$ & $\begin{array}{l}\text { Corresponde à questão 9.9 do instrumento de coleta de } \\
\text { dados: acredito que a união de organizações da sociedade } \\
\text { civil e órgãos governamentais é muito importante para o } \\
\text { desenvolvimento }\end{array}$ \\
\hline
\end{tabular}

Fonte: Dados da pesquisa.

\section{ESTATÍSTICA DESCRITIVA}

Todas as informações quantitativas, sejam elas de natureza primária ou secundária, foram analisadas à luz das medidas de tendência central, distribuição de frequências e análise gráfica.

\section{Alpha de Cronbach}

A consistência interna dos dados primários foi testada pelo coeficiente de confiabilidade alfa de Cronbach. Segundo Hair et al. (2009) e Otobo, Santana e Costa (2016), o limite inferior para aceitação deste indicador é 0,70, mas em pesquisas exploratórias admite-se 0,60.

\section{Análise Fatorial Exploratória}

A técnica multivariada de Análise Fatorial Exploratória (AFE) foi utilizada para fazer o tratamento dos dados primários, oriundos da aplicação de questionários. Para Hair et al (2009, p. 33), trata-se de "uma abordagem estatística que pode ser usada para analisar inter-relações entre um grande número de variáveis e explicar essas variáveis em termos de suas dimensões inerentes comuns (fatores)".

O objetivo desta técnica é descrever a variabilidade original de um vetor aleatório $X$, explicado pela seguinte expressão:

$$
X_{i}=\alpha_{i} F+\varepsilon_{i}
$$

em que: é a variável $i$ padronizada para a obtenção de médias iguais a zero e desvios padrão iguais a 1 (Z scores); é uma constante que representa a carga fatorial, responsável por mensurar a importância dos fatores na composição das variáveis $i$; é um fator aleatório comum e; é o componente aleatório (erro) presente na mensuração de todas as variáveis i. (SANTANA et al., 2016; COSTA et al., 2017).

Nesta perspectiva, o fator constitui-se como a parte da variação total dos dados que pode ser explicada pelo conjunto das variáveis que o compõem, conforme a expressão 2: 


$$
X_{i}=\alpha_{i 1} F_{1}+\alpha_{i 2} F_{2}+\alpha_{i 3} F_{3}+\cdots+\alpha_{i j} F_{j}+\varepsilon_{i}
$$

em que: são as variáveis padronizadas, as cargas fatoriais, são os fatores comuns e é a magnitude de variação da variável $i$ que não é explicada pelo fator nem por outra variável do conjunto analisado (SANTANA et al., 2016; COSTA et al., 2017).

A delimitação do número de fatores deu-se pelo critério da raiz latente, conforme Santana (2007) e Hair et al. (2009). Neste contexto, todos os autovalores inferiores a 1 foram desconsiderados. O método de rotação ortogonal Varimax foi utilizado para rotação dos fatores, a fim de aumentar o poder de explicação da AFE e facilitar a interpretação dos resultados (FERREIRA et al., 2016; BECKMANN; SANTANA, 2017).

Os testes de Kaiser-Meyer-Olkin (KMO) e de Esfericidade de Bartlett foram utilizados como parâmetro para aferir a qualidade das correlações entre as variáveis. $O$ teste KMO é uma estatística que se situa no intervalo de zero a um. Resultados superiores a 0,6 são aceitáveis, mas quanto mais próximo de 1, maior é a adequação dos dados à AFE (HAIR et al., 2009; SANTANA et al., 2016).

\section{RESULTADOS E DISCUSSÕES}

A presente seção está dividida em três tópicos. O primeiro apresenta a caracterização socioeconômica do Território da Cidadania em foco neste artigo. O segundo mostra a percepção dos atores entrevistados, quanto aos níveis de participação institucional e gestão social e, na terceira parte, são apresentados os resultados da análise quantitativa que revela as dimensões da gestão social e participação institucional no território Noroeste Colonial.

\section{Caracterização socioeconômica do Território da Cidadania Noroeste Colonial RS}

O Território da Cidadania do Noroeste Colonial RS estende-se por uma área de aproximadamente 13,3 mil km², é composto por 34 municípios e possui duas áreas indígenas, conforme é possível observar na Figura 1. 
Figura 1 - Localização geográfica do Território da Cidadania Noroeste Colonial RS

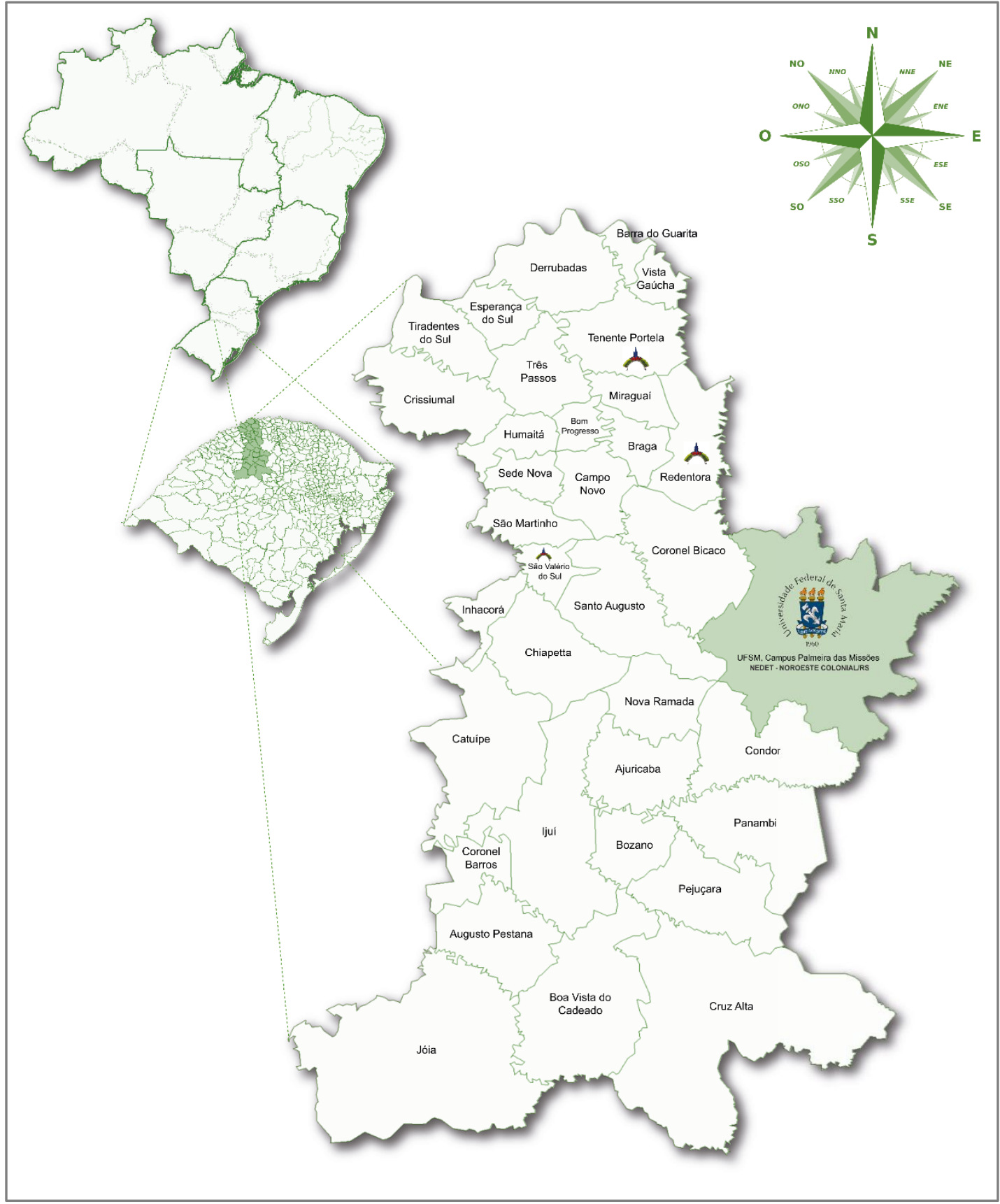

Fonte: Dados da pesquisa.

O território é caracterizado pela concentração de atividades rurais, predominantemente desenvolvidas por agricultores familiares. Apenas 8 dos 34 municípios possuem população superior a 10 mil habitantes, a população feminina foi estimada em 192,4 mil e a população masculina em 184,9 mil (BRASIL, 2013).

As maiores densidades demográficas são registradas nos municípios de ljuí, Três Passos, Panambi, Barra do Guarita e Cruz Alta. A característica do Território, contudo, é de municípios eminentemente pequenos e ruralizados, nos quais predominam as atividades da agricultura familiar, envolvendo a produção de leite, carne, ovos e grãos (Figura 2). Entre as maiores áreas destacam-se os municípios de Cruz Alta, Joia, Boa Vista do Cadeado, ljuí e Catuípe, todos com área superior a $500 \mathrm{~km}^{2}$. 
Figura 2 - Área territorial e densidade demográfica dos municípios integrantes do Território da Cidadania Noroeste Colonial/RS, 2010

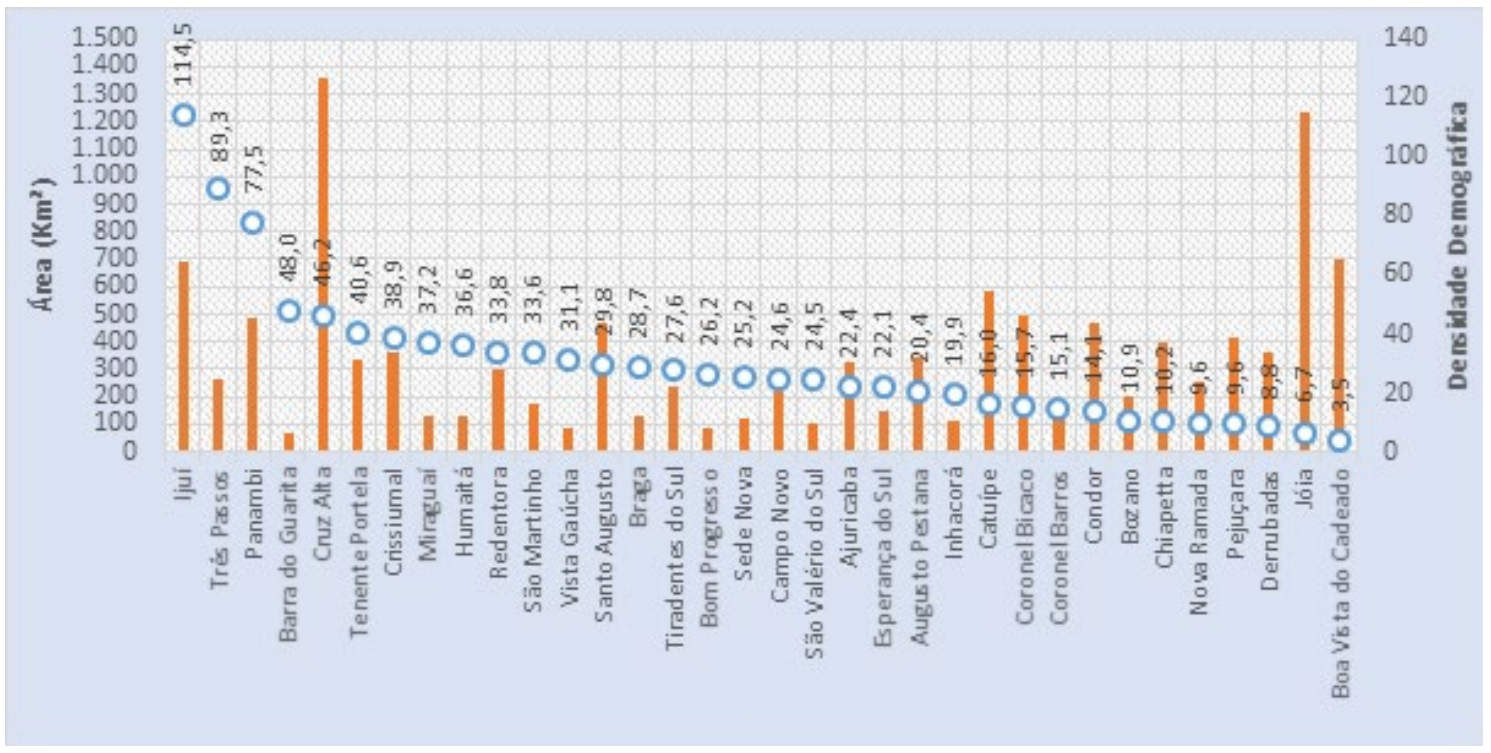

Fonte: BRASIL (2013).

Considerando que a população rural do território é de 99,6 mil habitantes (BRASIL, 2013) e que a maioria da população enquadra-se na categoria de agricultores familiares, nos termos da Lei № 11.326/2006, as atividades de extensão constituem-se como um importante elemento de dinamização do desenvolvimento rural. Nesse sentido, observa-se na Figura 3 que a população rural de 26 municípios do território é superior à população urbana e, em alguns casos, chega a ser quatro vezes maior, como é o caso de São Valério do Sul e Boa Vista do Cadeado.

Figura 3 - Efetivo da população rural e taxa de ruralização (População Rural/População Urbana) dos municípios integrantes do Território da Cidadania Noroeste Colonial/RS, 2010

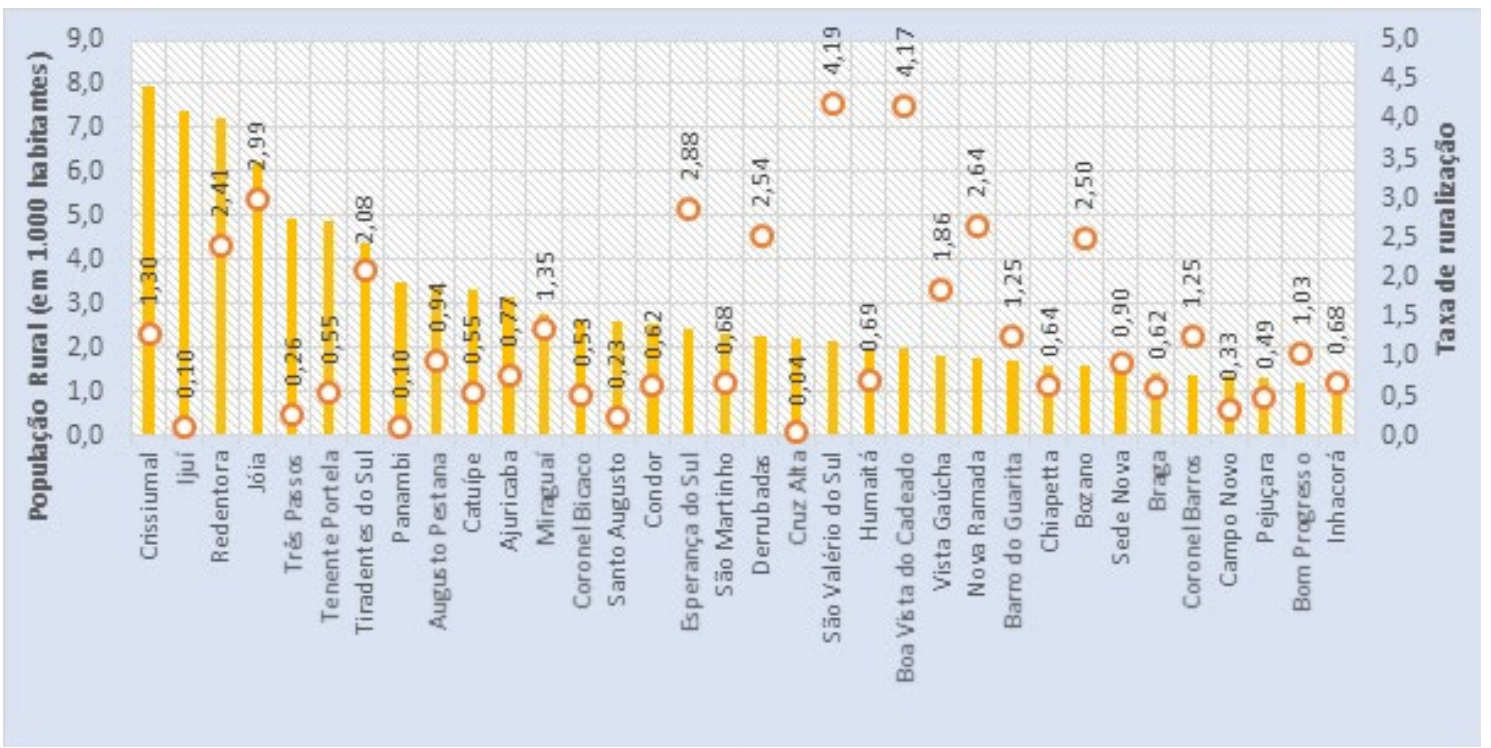

Fonte: BRASIL (2013). 
Em $47 \%$ dos municípios, portanto, o percentual da população empregada em atividades agropecuárias é superior a 50\%, chegando a 76\% em Esperança do Sul, 74\% em Tiradentes do Sul e 72\% em Nova Ramada. Por outro lado, evidenciou-se a redução da importância relativa do segmento agropecuário entre 2000 e 2010, uma vez que em todos os munícipios analisados houve redução relativa na ocupação no setor agropecuário (Figura 4).

Figura 4 - Percentual de ocupados no setor agropecuário nos municípios do Território da Cidadania Noroeste Colonial/RS, 2010

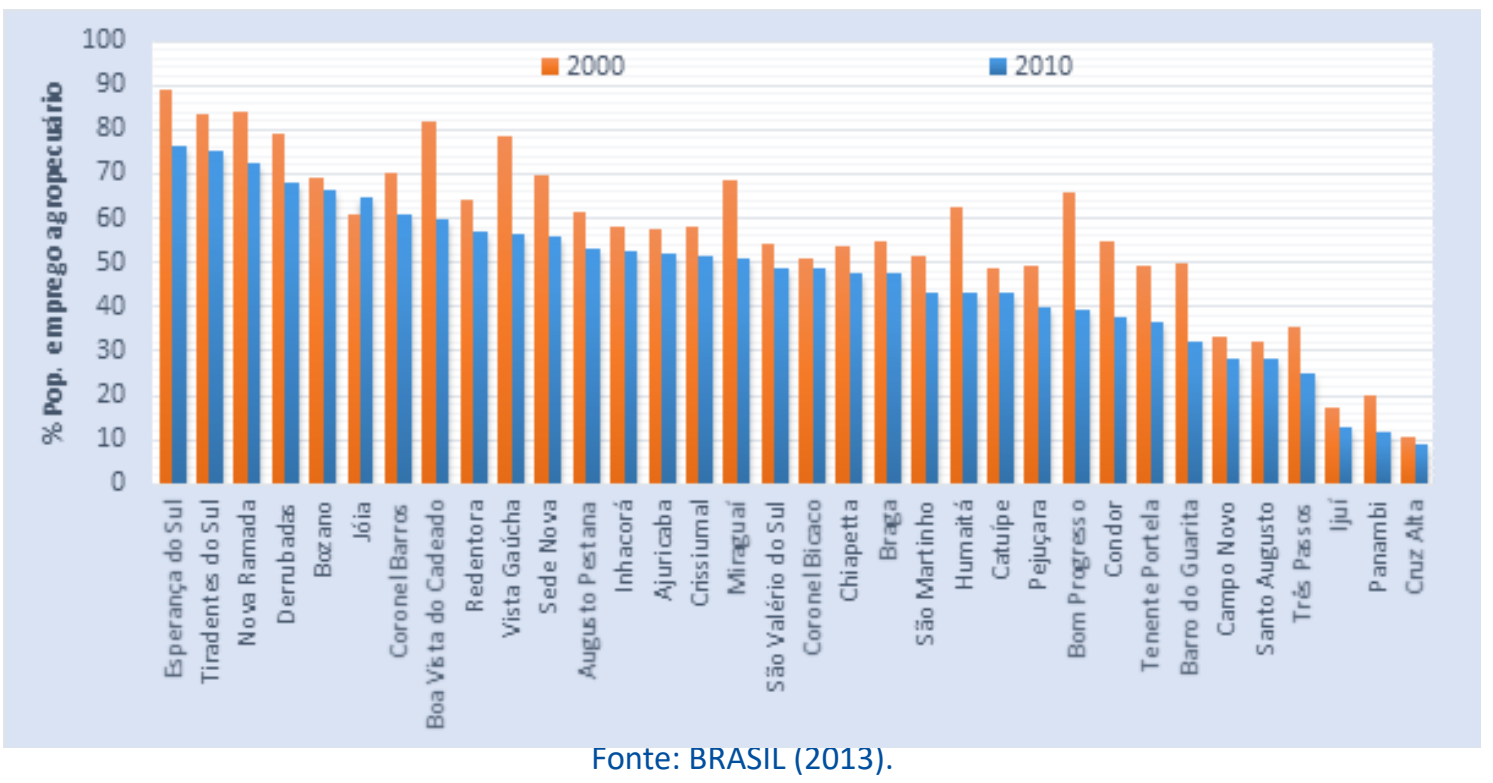

O território também é caracterizado por municípios com altas taxas de analfabetismo da população de 18 anos ou mais de idade. Nesse sentido, observou-se o grau de analfabetismo de 17,5\% em Redentora, 14,9\% em Braga, 14,8\% em São Valério do Sul e aproximadamente 14\% em Campo Novo (Figura 5). Esse quadro, contudo, apresentou evidente melhoria após 1991, dado que em todos os municípios foi constatada a redução do analfabetismo da população. Neste caso, em específico, Costa et al. (2017) já destacaram a necessidade de intensificar as ações da política educacional, sobretudo porque ela está diretamente relacionada aos processos de formação de capital humano e de desenvolvimento regional.

Com efeito, a educação deve ser considerada uma preocupação a ser enfrentada pela política pública, pois nenhum município possui IDH-M Educação superior a 0,8 (condição ideal), apesar da sensível melhora em relação a 1991 e 2000, momentos em que a predominância era de baixos índices em todos os municípios. Neste indicador, somente Três Passos e ljuí alcançaram patamares superiores a 0,7 e 11 municípios não alcançaram o coeficiente 0,6 .

O grau de concentração de renda nos municípios do Território, mensurado pelo Índice de Gini, que se destina a analisar a distribuição dos rendimentos e enquadrar nos diversos estratos, com vistas a demonstrar a polarização da renda entre os mais ricos e os mais pobres, mostra que em $47 \%$ dos municípios o índice analisado ficou em patamar superior a 0,5 , o que corrobora a existência de desigualdades importantes no rendimento das populações (BRASIL, 2013). 
Figura 5 - Taxa de analfabetismo da população de 18 anos ou mais de idade do Território da Cidadania Noroeste Colonial/RS, 2010

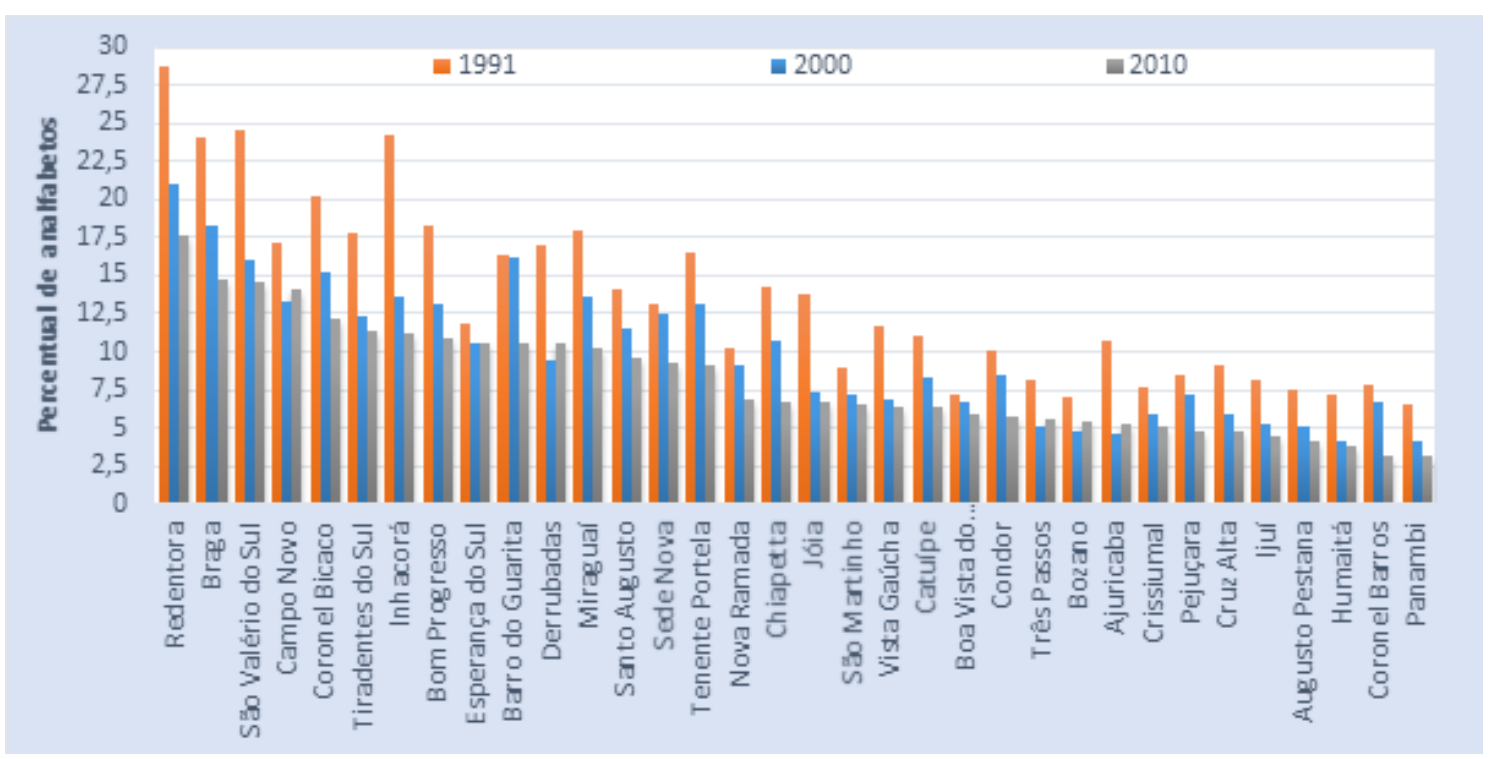

Fonte: BRASIL (2013).

Neste contexto, no estrato em que se enquadra a categoria de pobres segundo a renda, a proporção de pessoas com renda per capita inferior a $\mathrm{R} \$ 140,00 /$ mês reduziu-se significativamente no período 1991 - 2000 e 2000 - 2010. Mesmo assim, identificou-se que em municípios como Redentora mais de $40 \%$ da população é pobre. Isso contrasta com indicadores como o de Panambi, em que $5 \%$ da população vive com menos de R\$ 140,00 por mês e indica as severas desigualdades existentes no Território da Cidadania Noroeste Colonial (BRASIL, 2013).

As desigualdades ficam mais evidentes quando a estatística analisada é a proporção dos indivíduos com renda domiciliar per capita igual ou inferior a $\mathrm{R} \$$ 70,00 mensais, ou seja, proporção de extremamente pobres. Nesse contexto, apesar de identificar a melhoria nos indicadores de todos os municípios, ainda temos situações de municípios em que $30 \%$ da população é extremamente pobre. Este dado, associado às estatísticas da proporção de crianças em vulnerabilidade social (Figura 6), corrobora a importância de ampliar as políticas públicas de desenvolvimento territorial, pois apesar do êxito aparente, na maioria dos municípios, em reduzir a proporção de crianças extremamente pobres, uma parcela importante ainda está com indicadores desfavoráveis.

Outra característica do Território em análise é a grande diferença na renda per capita média dos municípios. Nessa perspectiva, a diferença entre o município de maior renda (Coronel Barros, $\mathrm{R} \$ 1.112,14$ ) e o de menor renda (Redentora, $\mathrm{R} \$ 346,40$ ) chega a R\$ 765,74 (BRASIL, 2013).

Outro importante indicador de pobreza é dado pela razão entre as pessoas que vivem em domicílios vulneráveis à pobreza (com renda per capita inferior a 1/2 salário mínimo de agosto de 2010) e nos quais a principal fonte de renda provém de moradores com 65 anos ou mais de idade e população total residente em domicílios particulares permanentes multiplicado por 100 . Nesse contexto, observa-se que nos últimos anos, em especial a partir de 2000, houve significativa melhora, uma vez que quantitativo importante da população deixou de depender da renda de idosos, mas ainda existe a necessidade de construir alternativas e promover políticas de desenvolvimento regional. 
Figura 6 - Proporção de crianças extremamente pobres (renda per capita inferior a R\$70,00/ mês) nos municípios do Território da Cidadania Noroeste Colonial/RS, 2010

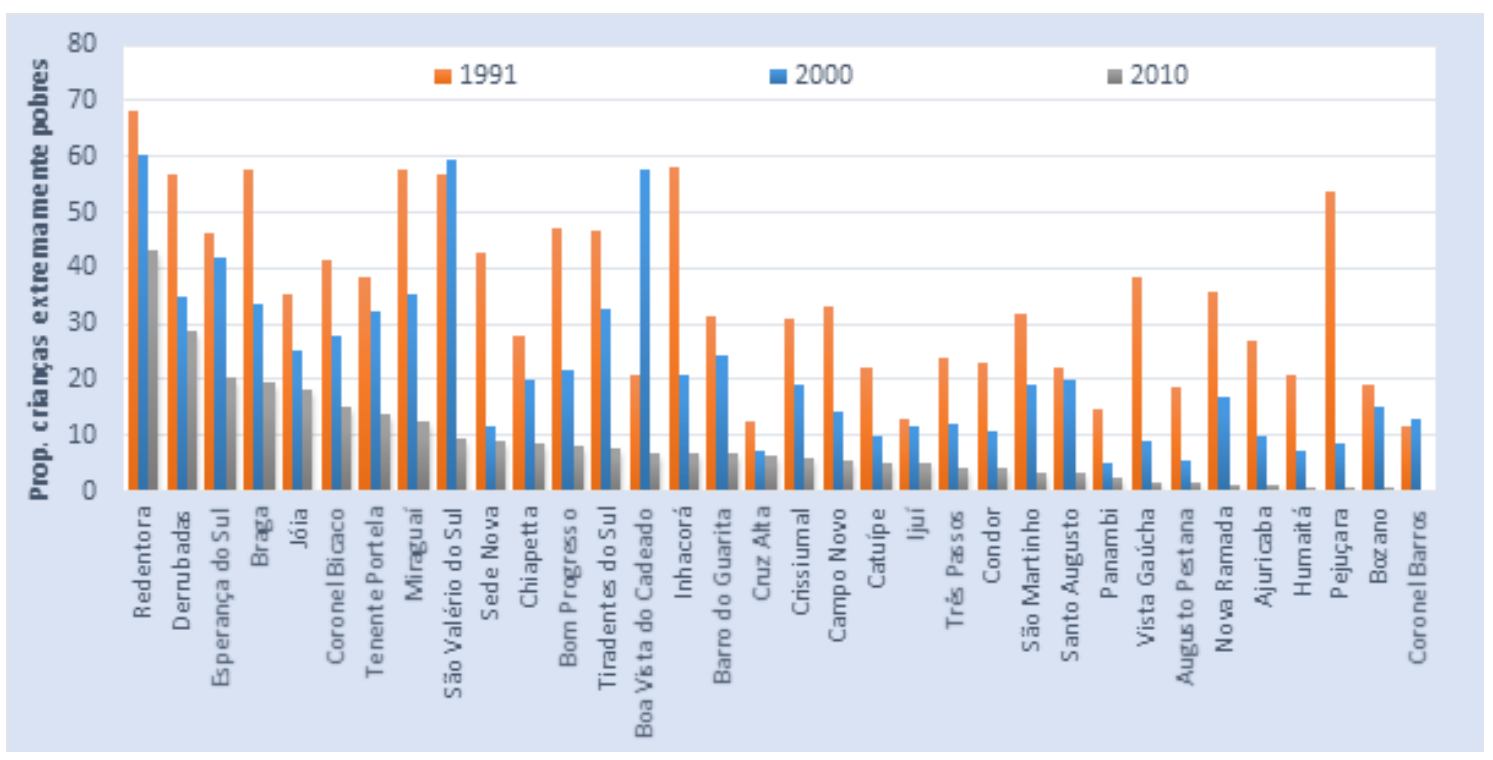

Fonte: BRASIL (2013).

Por outro lado, os indicadores relacionados à saúde e longevidade mostram que apenas três municípios (Coronel Bicaco, Redentora e Esperança do Sul) ainda não alcançaram a condição ideal. Os avanços apresentados nas últimas décadas, contudo, permitem identificar uma tendência de melhoria. Analogamente, a análise da evolução do IDH-M Renda, mostra avanços em todos os municípios, mas nenhum conseguiu chegar no patamar de alto desenvolvimento.

Em decorrência do fraco desempenho na maioria dos indicadores de saúde, educação e renda, todos os municípios do Território da Cidadania Noroeste Colonial possuem IDH-M inferior a 0,8, conforme é possível observar na Figura 7.

Figura 7 - IDH-M dos municípios do Território da Cidadania Noroeste Colonial/RS, 2010

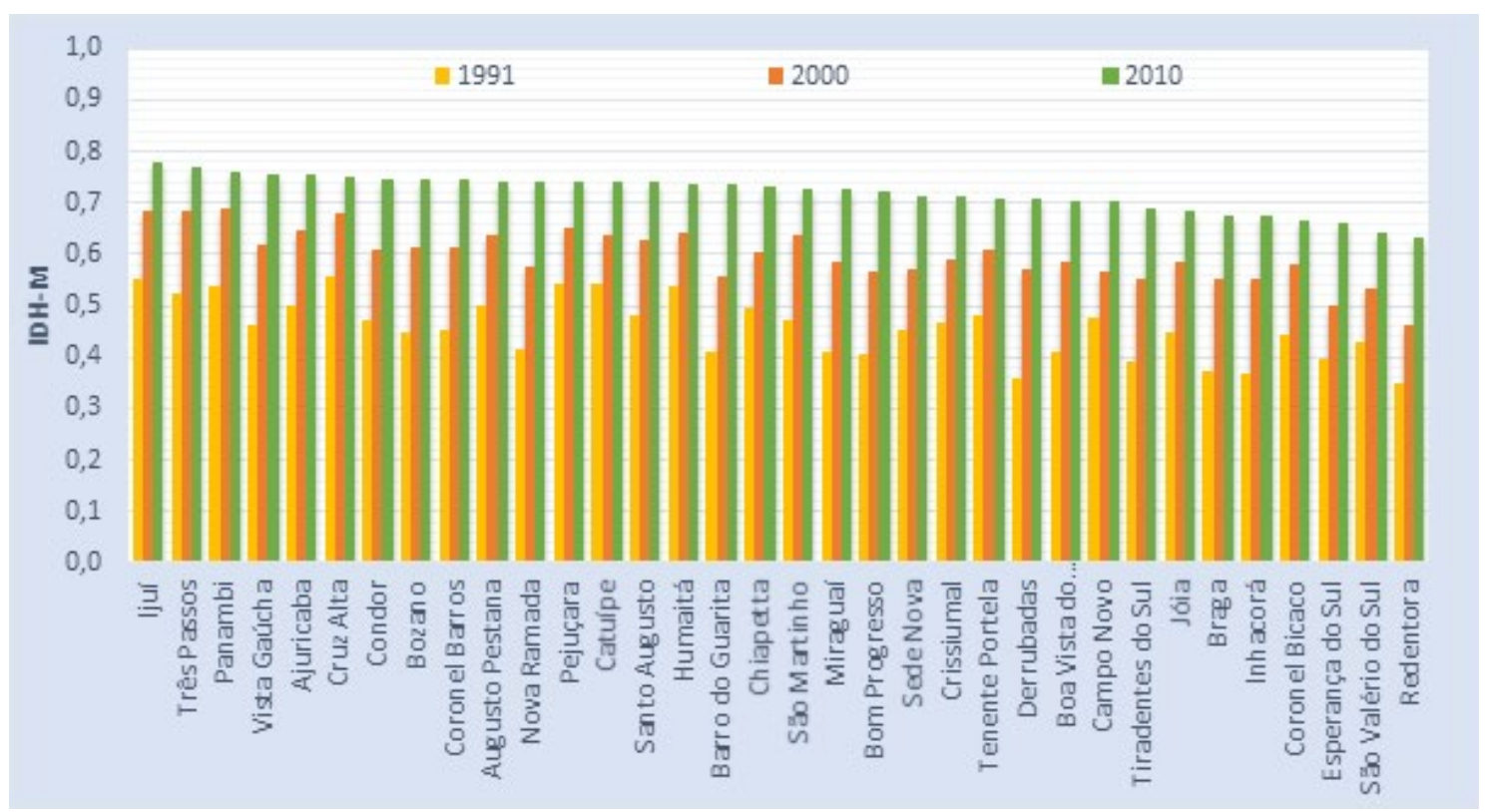

Fonte: BRASIL (2013). 
Por tudo isso, as instituições presentes no Território, em especial o Colegiado de Desenvolvimento Territorial, os Conselhos Regionais de Desenvolvimento, os Conselhos Municipais de Desenvolvimento, sindicatos e sociedade civil organizada possuem um importante papel no processo de fortalecimento do capital social, mediante organização dos produtores com vistas a reduzir os custos de transação no sentido proposto por Williamson (1979). Este é o segundo objetivo desta pesquisa, que passa a ser apresentado a seguir.

\section{Participação Institucional, Gestão e Capital Social no Território da Cidadania Noroeste Colonial}

Os níveis de participação institucional, gestão e capital social no Território foram aferidos a partir da aplicação de 116 questionários, conforme descrito no referencial metodológicos. Destes, foram aproveitados 97 . Os demais foram descartados por apresentarem número elevado de questões não respondidas.

As questões consideradas relevantes para o trabalho foram aferidas a partir da escala de Likert, que apresentou cinco possibilidades de resposta: 1. Discordo totalmente, 2. Discordo parcialmente, 3. Não concordo nem discordo, 4. Concordo parcialmente e 5. Concordo totalmente. A escala de Likert proporcionou condições de mensurar a intensidade com que o entrevistado concorda ou discorda de uma afirmação.

A Tabela 1 apresenta a média, mediana e moda das respostas dos entrevistados.

Tabela 1 - Medidas de tendência central das variáveis da pesquisa

\begin{tabular}{|c|c|c|c|}
\hline Variável & $\begin{array}{l}\text { Média } \\
\text { (Me) }\end{array}$ & $\begin{array}{c}\text { Mediana } \\
\text { (Md) }\end{array}$ & $\begin{array}{l}\text { Moda } \\
\text { (Mo) }\end{array}$ \\
\hline$X_{7}$. Comudes é atuante & 4,02 & 4,00 & 5 \\
\hline $\mathrm{X}_{8}$. Conselho de Desenvolvimento Rural é atuante & 3,95 & 4,00 & 5 \\
\hline$X_{1}$. Minha instituição integra o Codeter & 3,27 & 3,00 & 5 \\
\hline$X_{2}$. Codeter é espaço para discutir projetos estratégicos & 3,86 & 4,00 & 5 \\
\hline $\mathrm{X}_{3}$. Codeter sabe as metas que deve alcançar & 2,70 & 3,00 & 3 \\
\hline $\mathrm{X}_{4}$. Movimentos Sociais possuem atuação relevante no Codeter & 3,22 & 3,00 & 3 \\
\hline$X_{5}$. Prefeituras possuem atuação relevante no Codeter & 3,32 & 4,00 & 5 \\
\hline$X_{6}$. Órgãos públicos possuem atuação relevante no Codeter & 3,18 & 3,00 & 3 \\
\hline$X_{9}$. Projetos tramitados no Território são discutidos & 2,98 & 3,00 & 3 \\
\hline$X_{13}$. No território, direitos e deveres são iguais & 3,56 & 4,00 & 5 \\
\hline $\mathrm{X}_{14}$. Existe cooperação nas pautas do Codeter & 3,95 & 4,00 & 5 \\
\hline $\begin{array}{l}X_{15} \text { O principal interesse dos membros do Codeter é o desenvolvimento da } \\
\text { região }\end{array}$ & 4,27 & 5,00 & 5 \\
\hline $\begin{array}{l}\text { X16. A união da sociedade civil e órgãos governamentais é importante para } \\
\text { o desenvolvimento }\end{array}$ & 4,54 & 5,00 & 5 \\
\hline$X_{10}$. A gestão social do território favorece o desenvolvimento local & 4,03 & 4,00 & 5 \\
\hline$X_{11}$. As mulheres participam das discussões de desenvolvimento rural & 3,46 & 4,00 & 4 \\
\hline $\mathrm{X}_{12}$. Os jovens participam das discussões de desenvolvimento territorial & 3,07 & 3,00 & 4 \\
\hline
\end{tabular}

Fonte: Dados da pesquisa.

De modo geral, foi possível identificar que: 
a. Na percepção dos entrevistados, os Conselhos Municipais de Desenvolvimento Econômico (Comudes) e de Desenvolvimento Rural são atuantes, uma vez que a média e mediana das respostas ficou ao redor de 4 e a resposta que mais se repetiu foi 5 .

b. O Codeter se constitui como espaço para discutir projetos estratégicos ( $\mathrm{Me}=$ $3,86, \mathrm{Md}=4$ e $\mathrm{Mo}=5$ ), mas precisa definir melhor as metas, uma vez que a média, mediana e moda da variável $X_{3}$ foi 2,7, 3,0 e 3,0.

c. A relevância da participação dos movimentos sociais, prefeituras e órgãos públicos é discreta, se avaliada pela média das respostas das variáveis $\mathrm{X}_{4}, \mathrm{X}_{5}$ e $\mathrm{X}_{6}$.

d. Os projetos tramitados no território são discutidos no Codeter, mas é necessário um adensamento nesta prática, uma vez que a variável $\mathrm{X}_{9}$ apresentou $\mathrm{Me}=$ 2,98 e Md e $\mathrm{Mo}=3,0$.

e. A percepção de igualdade de gênero nas discussões territoriais, de cooperação e confiança e de união entre os entrevistados, principalmente pela média, mediana e moda das variáveis $\mathrm{X}_{13}, \mathrm{X}_{14}, \mathrm{X}_{15}$ e $\mathrm{X}_{16}$.

f. A gestão social do território favorece o desenvolvimento local.

g. Os jovens e mulheres participam das discussões, mas podem ampliar a sua importância na política de desenvolvimento territorial.

Na Figura 8 pode-se visualizar os resultados de acordo com a percepção dos entrevistados.

Figura 8 - Distribuição de frequências das variáveis utilizadas na pesquisa

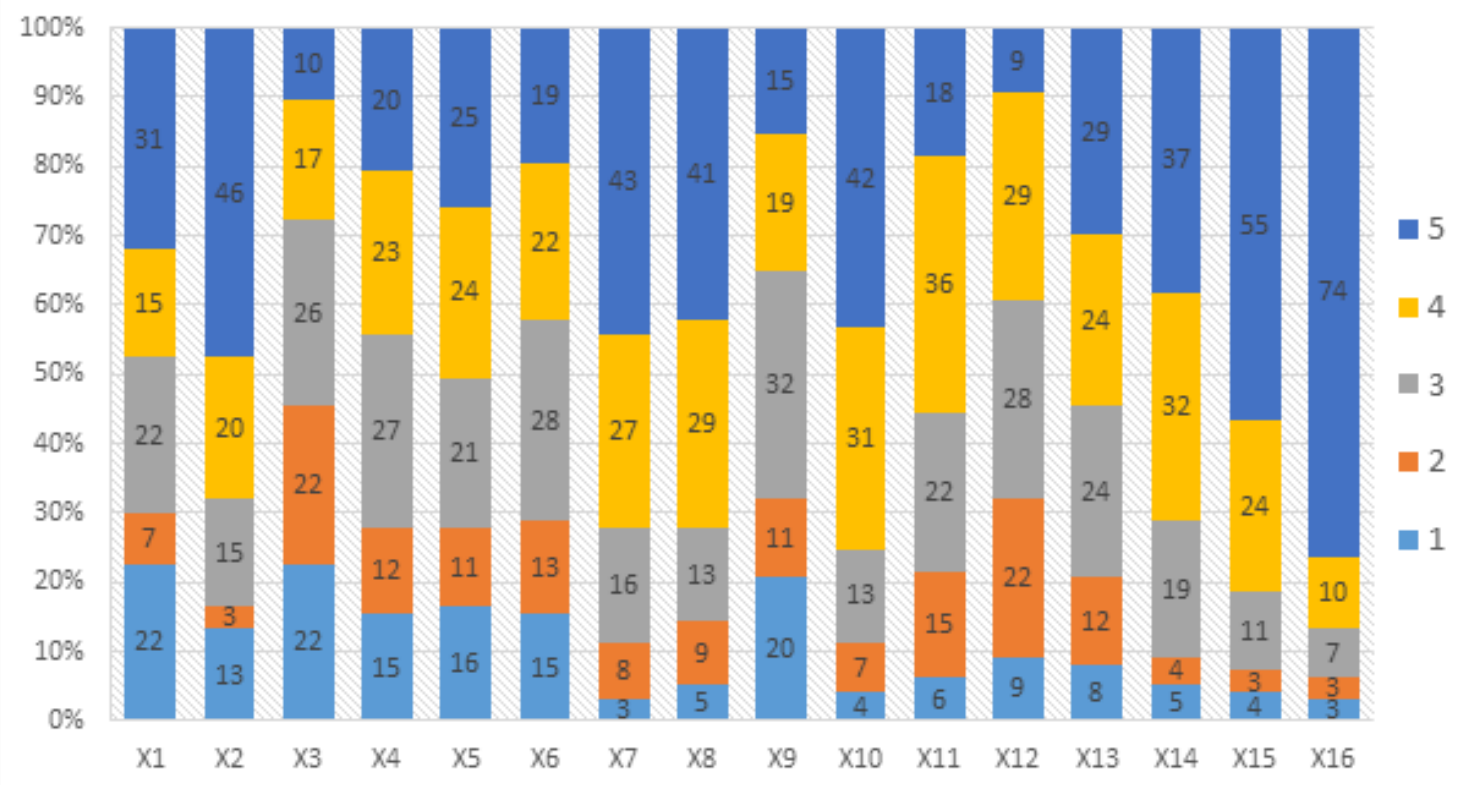

Fonte: Dados da pesquisa.

Nesse sentido, é possível observar que:

a. Para $60 \%$ dos entrevistados, os jovens não participam ativamente das discussões, variável $\mathrm{X}_{12}$.

b. Para $70 \%$ dos entrevistados, o Codeter não sabe exatamente as metas que deve alcançar, variável $\mathrm{X}_{3}$. 
c. Para $58 \%$ dos entrevistados a atuação dos órgãos públicos não foi muito relevante, mas cerca de $88 \%$ acreditam que a união da sociedade civil e órgãos governamentais é importante para o desenvolvimento. A interpretação deste resultado deve levar em consideração que para cerca de $88 \%$ dos entrevistados os Conselhos Municipais (variáveis $X_{7}$ e $X_{8}$ ) são atuantes e, em grande medida, não vinham interagindo com o Codeter.

A consistência interna dos dados primários foi avaliada pelo coeficiente de confiabilidade alfa de Cronbach, que se situou no patamar de 0,879 . Considerando que o limite inferior para aceitação deste indicador, segundo Hair et al. (2009) e Otobo, Santana e Costa (2016), é 0,60 para pesquisas exploratórias, é possível afirmar que a escala interna dos dados é consistente e aponta para a relevância dos dados primários.

\section{As Dimensões da Gestão Social e Participação Institucional}

Com o objetivo de identificar dinâmicas e padrões no comportamento dos dados e, a partir disso construir categorias analíticas que estejam conectadas com as contribuições teóricas acerca do desenvolvimento territorial, os dados foram tratados pela técnica multivariada de Análise Fatorial Exploratória.

Identificou-se, no primeiro momento, que o determinante da matriz de correlação foi diferente de zero e situou-se no patamar de 0,001. Isto permite o cálculo da matriz inversa e, por consequência, uma solução para o sistema de equações intrínsecos à AFE (HAIR et al., 2009; COSTA et al., 2017).

Entre os critérios para manter e excluir variáveis do modelo destaca-se a avaliação dos coeficientes contidos na Matriz Anti-Imagem e as Comunalidades $\left(h^{2}\right)$. Nessa perspectiva, apenas as variáveis $X_{16}$ e $X_{10}$ apresentaram comunalidade $\left(h^{2}\right)$ inferior a 0,60. Hair et al (2009) recomenda que $h^{2}$ seja sempre superior a 0,60, mas admite a possibilidade de manter variáveis que ultrapassem este limite, desde que sejam consideradas importantes para o conjunto da análise.

Os testes de Kaiser-Meyer-Olkin (KMO) e de Esfericidade de Bartlett foram utilizados para avaliar a adequação da amostra à técnica de AFE. Estes testes permitem identificar a qualidade das correlações entre as variáveis. O teste KMO apresentou coeficiente de 0,798 e de Bartlett de 666,74 (Sig. 0,000), ambos corroboram para a adequação da amostra.

A extração dos fatores pelo método dos Componentes Principais, e posterior rotação, pelo método Varimax, resultaram na identificação de cinco dimensões ou padrões de variabilidades existentes na matriz analisada. Juntas, estas dimensões explicaram 70,201\% da variância da nuvem de dados, conforme é possível verificar na Tabela 3.

As estruturas latentes reveladas pelos fatores, que não são observáveis pela análise isolada das variáveis, permitiram representar a organização e funcionamento e o alcance da política territorial no Território da Cidadania Noroeste Colonial.

Nesse contexto, a primeira dimensão fatorial agregou as variáveis $\mathrm{X}_{15}, \mathrm{X}_{16}, \mathrm{X}_{10} \mathrm{e}$ $\mathrm{X}_{14}$ e foi responsável por explicar cerca de $15,3 \%$ da variância dos dados. A associação destas variáveis, neste fator, configura um vetor de variabilidade nos dados que revela a existência de um processo de cidadania e participação que configura a dimensão como a construção de capital social, em que direitos, deveres, igualdade, confiança 
e engajamento são cristalizados a partir das noções de que o principal interesse dos membros do Codeter é o desenvolvimento da região, que a união da sociedade civil e órgãos governamentais é importante para o desenvolvimento, que a gestão social do território favorece o desenvolvimento local e que os membros cooperam nas discussões realizadas em âmbito de Codeter.

Tabela 3 - Matriz de Cargas Fatoriais $(\alpha)$ e Comunalidades $\left(\mathrm{h}^{2}\right)$

\begin{tabular}{|c|c|c|c|c|c|c|}
\hline \multirow{2}{*}{ Variáveis } & \multicolumn{5}{|c|}{ Cargas Fatoriais $(\alpha)$} & \multirow[t]{2}{*}{$h^{2}$} \\
\hline & 1 & 2 & 3 & 4 & 5 & \\
\hline $\begin{array}{l}\mathrm{X}_{15} \text { O principal interesse dos membros do } \\
\text { Codeter é o desenvolvimento da região }\end{array}$ & 0,8061 & 0,0552 & 0,1499 & 0,2133 & 0,1227 & 0,7360 \\
\hline $\begin{array}{l}\mathrm{X}_{16} \text { A união da sociedade civil e órgãos } \\
\text { governamentais é importante para o } \\
\text { desenvolvimento }\end{array}$ & 0,7815 & $-0,012$ & 0,2888 & 0,0593 & $-0,147$ & 0,7190 \\
\hline $\begin{array}{l}\mathrm{X}_{10} \text {. A gestão social do território favorece o } \\
\text { desenvolvimento local }\end{array}$ & 0,6800 & 0,1656 & 0,0648 & 0,2186 & 0,1065 & 0,5530 \\
\hline $\mathrm{X}_{14^{4}}$ Existe cooperação nas pautas do Codeter & 0,5630 & 0,3566 & 0,0054 & 0,3320 & 0,2072 & 0,5970 \\
\hline $\begin{array}{l}X_{2} \text {. Codeter é espaço para discutir projetos } \\
\text { estratégicos }\end{array}$ & 0,2131 & 0,7787 & 0,1555 & $-0,0357$ & 0,0315 & 0,6780 \\
\hline$X_{1}$. Minha instituição integra o Codeter & $-0,036$ & 0,7741 & 0,1979 & 0,2443 & 0,0800 & 0,7060 \\
\hline$X_{3}$. Codeter sabe as metas que deve alcançar & 0,1388 & 0,6068 & 0,3945 & 0,2632 & 0,0303 & 0,6130 \\
\hline $\begin{array}{l}X_{5} . \text { Prefeituras possuem atuação relevante no } \\
\text { Codeter }\end{array}$ & 0,1602 & 0,2534 & 0,7802 & 0,2063 & 0,0970 & 0,7510 \\
\hline $\begin{array}{l}\mathrm{X}_{6} \text {. Órgãos públicos possuem atuação } \\
\text { relevante no Codeter }\end{array}$ & 0,2100 & 0,3087 & 0,7507 & 0,0537 & 0,2965 & 0,7940 \\
\hline $\begin{array}{l}\mathrm{X}_{4} \text {. Movimentos sociais possuem atuação } \\
\text { relevante no Codeter }\end{array}$ & 0,1036 & 0,5166 & 0,6736 & 0,0516 & 0,1144 & 0,7470 \\
\hline $\begin{array}{l}\mathrm{X}_{12} \text {. Os jovens participam das discussões de } \\
\text { desenvolvimento territorial }\end{array}$ & 0,2254 & $-0,077$ & 0,5643 & 0,5268 & 0,0255 & 0,6530 \\
\hline $\begin{array}{l}\mathrm{X}_{11} \text {. As mulheres participam das discussões de } \\
\text { desenvolvimento rural }\end{array}$ & 0,2394 & $-0,089$ & 0,1297 & 0,7992 & 0,0874 & 0,7280 \\
\hline$X_{13}$. No território, direitos e deveres são iguais & 0,2021 & 0,3262 & 0,0700 & 0,7419 & 0,1462 & 0,7240 \\
\hline $\begin{array}{l}X_{9} \text {. Projetos tramitados no Território são } \\
\text { discutidos }\end{array}$ & 0,1416 & 0,3488 & 0,1517 & 0,7074 & $-0,072$ & 0,6700 \\
\hline$X_{7}$. Comudes é atuante & 0,2849 & 0,1484 & 0,0288 & 0,0713 & 0,8262 & 0,7920 \\
\hline $\begin{array}{l}\mathrm{X}_{8} \text {. Conselho de Desenvolvimento Rural é } \\
\text { atuante }\end{array}$ & $-0,1191$ & $-0,0206$ & 0,2756 & 0,0557 & 0,8226 & 0,7700 \\
\hline Soma de quadrados do autovalor & 2,4508 & 2,4222 & 2,3950 & 2,3605 & 1,6037 & 11,2321 \\
\hline Percentual do traço & 15,318 & 15,139 & 14,969 & 14,753 & 10,023 & 70,201 \\
\hline
\end{tabular}

Fonte: Dados da pesquisa.

O segundo fator, correspondente a $15,1 \%$ da variância dos dados, agrega as variáveis $X_{2}, X_{1}$ e $X_{3}$. Neste, observa-se a associação entre a percepção daqueles que participam do Codeter e acreditam que o colegiado se constitui como lócus para discutir os projetos estratégicos e definir as metas a serem alcançadas. Em função disso revela-se uma dimensão que corrobora o comprometimento e o foco dos participantes em relação às questões territoriais, que pode ser denominado de governança territorial. Neste caso, também revela a confiança e a organização do colegiado. 
$\mathrm{Na}$ terceira dimensão ou categoria analítica associaram-se as variáveis $\mathrm{X}_{5^{\prime}}, \mathrm{X}_{6}, \mathrm{X}_{4}$ e $X_{12}$. Este é um fator que reconhece a atuação das prefeituras, órgãos públicos e das jovens, o que ratifica a percepção de integração entre os diferentes atores territoriais, que pode ser denominado de arranjo institucional. Esta dimensão respondeu por cerca de $15 \%$ da variância explicada.

O quarto fator, responsável por $14,8 \%$ da variância explicada, revela a dimensão igualdade de gênero, pois agrega as variáveis $\mathrm{X}_{11}, \mathrm{X}_{13}$ e $\mathrm{X}_{9}$, todas relacionadas à participação das mulheres, à igualdade de direitos e deveres e ao processo de discussão da política territorial.

O quinto fator surgiu das ações territoriais voltadas para o Desenvolvimento Econômico e de Desenvolvimento Rural, responsável por $10 \%$ da variância dos dados. Este fator revelou a dimensão política pública municipal e agregou as variáveis $\mathrm{X}_{7}$ e $\mathrm{X}_{8}$.

Os resultados desta pesquisa corroboram a percepção de Deckert (2017, p. 426), de que:

(...) o programa Territórios da Cidadania pratica a gestão social no Noroeste Gaúcho, principalmente na articulação da sociedade civil para pleitear o programa para a região, sentindo-se parte dele. O TC-Norc é um espaço onde os indivíduos que, em outros programas, sentiam-se excluídos, têm oportunidade de expressar as dificuldades sentidas em seu meio, especialmente os públicos especiais, que são: povos indígenas, assentados da reforma agrária e agricultura familiar.

Por outro lado, mesmo com os avanços alcançados nos últimos anos, os desafios a serem superados, neste território, ainda são consideráveis.

Naturalmente os níveis de engajamento e formação de capital social, assim como os de participação institucional, podem e devem melhorar, mas destaca-se que a institucionalidade Codeter se propôs a realizar um trabalho em prol do desenvolvimento territorial e da inclusão de públicos específicos. Nessa perspectiva, a análise corrobora com o processo latente de formação de capital social e este tende a facilitar a cooperação espontânea, fortalece os sistemas de participação cívica, nos termos dados por Putnam (2000), que conduzem à governança das ações de políticas públicas de desenvolvimento rural dos municípios do território estudado.

\section{CONSIDERAÇÕES FINAIS}

Identificou-se que o Território da Cidadania Noroeste Colonial do Rio Grande do Sul constitui-se como um espaço em transformação, que está sendo pensado e instituído com o esforço conjunto dos atores que compõem o Colegiado de Desenvolvimento Territorial.

A busca pelo desenvolvimento territorial foi objeto de reflexão na maior parte das ações do Codeter e o público entrevistado revelou esta percepção.

Os avanços nos indicadores socioeconômicos das últimas décadas foram importantes, mas insuficientes para proporcionar redução nas assimetrias regionais e qualidade de vida para toda a população do Território. Neste conjunto importante de questões que devem ser superadas, destacam-se, principalmente, aquelas relacionadas à pobreza, baixos índices de alfabetização e de baixa renda domiciliar per capita em municípios específicos. 
Os resultados revelaram que a interação institucional do Território da Cidadania Noroeste Colonial RS está liderando o planejamento do desenvolvimento territorial. Apesar das dificuldades econômicas enfrentadas, as instituições que fazem a interlocução com o Colegiado de Desenvolvimento Territorial apresentaram destaque na construção de capital social e sua contribuição na execução de ações de desenvolvimento territorial.

Dessa forma, os níveis de engajamento e construção de capital social, assim como os de participação institucional, estão presentes no avanço do Codeter e na sua capacidade de articular diferentes atores sociais e discutir processo de desenvolvimento territorial.

Por fim conclui-se, conforme revelado nos resultados da análise fatorial, que a trajetória de desenvolvimento territorial está sendo alavancada por forças que andam na direção do crescimento com inclusão social.

\section{REFERÊNCIAS}

ABRAMOVAY, R. Agricultura familiar e desenvolvimento territorial. Reforma Agrária, v. 28, n. 1, p. 2, 1998. ABRAMOVAY, R. O capital social dos territórios: repensando o desenvolvimento rural. Economia Aplicada, v. 4, n. 2, p. 379-397, 2000.

BECKMANN, E.; SANTANA, A. C. Indicadores da modernização agrícola do Estado de Mato Grosso. Extensão Rural, v. 24, n. 1, p. 100-119, 2017.

BRASIL. Atlas do Desenvolvimento Humano no Brasil. [s.I.]: Pnud; Ipea; FJP, 2013.

COSTA, N. L. et al. Capital humano e desenvolvimento econômico no Rio Grande do Sul: uma abordagem multivariada. Desenvolvimento em Questão, v. 15, n. 38, p. 380-402, 2017.

COSTA, N. L.; SANTANA, A. C.; MATTOS, C. A. C. Análise dos determinantes da produção agropecuária do Rio Grande do Sul. Ensaios FEE, v. 36, n. 1, p. 159-178, 2014.

DECKERT, C. T. Configuração do poder no Codeter: uma análise do território da cidadania Noroeste Colonial-RS/Configuration of power in Codeter: an analysis of the Territory of Citizenship Noroeste Colonial-RS. Redes, v. 22, n. 1, 2017.

DURSTON, J. Building Social Capital in Rural Communities (where it doesn't exist). Theoretical and Policy Implications of Peasant Empowerment in Chiquimula, Guatemala. Latin American Studies Association (Lasa), The Palmer House Hilton, Chicago, IL, september 24-26, 1998.

FERNANDES, B. M. Questão agrária: conflitualidade e desenvolvimento territorial. Campinas: Editora Unicamp, 2004.

FERREIRA, V. A. et al. Os fatores de repercussão da cadeia produtiva do dendê no desenvolvimento local do Baixo Tocantins. Desenvolvimento e Meio Ambiente, v. 39, p. 173-188, 2016.

GORDILLO DE ANDA, G. The reconstruction of rural institutions. Rome: FAO, 1997.

HAIR, J. F. et al. Análise multivariada de dados. Porto Alegre: Bookman Editora, 2009.

OTOBO, A. O.; SANTANA, A. C.; COSTA, C. F. Índice de responsabilidade socioambiental empresarial no distrito administrativo de Icoaraci (Daico). Revista Brasileira de Gestão e Desenvolvimento Regional, Belém, Pará, v. 12, n. 2, p. 287-310, 2016.

PRESTES, R. M.; FLORES, A. J. Plano territorial de desenvolvimento rural sustentável -PTDRS. Revista de Administração, v. 5, n. 8, p. 89-106, 2013.

PUTNAM, R. D. Comunidade e democracia: a experiência da Itália moderna. Rio de Janeiro: FGV Editora, 2000.

SANTANA, A. C. Análise do desempenho competitivo das agroindústrias de polpa de frutas do Estado do Pará. Teoria e Evidência Econômica, v. 14, n. 1, p. 36-62, 2007.

SANTANA, A. C. et al. O valor econômico total da área de savana metalófita, ou "canga", da Floresta Nacional de Carajás, estado do Pará: uma contribuição teórica e metodológica da avaliação contingente. Papers do NAEA, v. 361, n. 1, p. 1-48, 2016.

STIGLITZ, J. Distribution, efficiency and voice: designing the second generation of reforms. In: Conference on Asset Distribution, Poverty and Economic Growth, Brasília, 1998. p. 98.

WILLIAMSON, O. E. Transaction-cost economics: the governance of contractual relations. The journal of Law and Economics, v. 22, n. 2, p. 233-261, 1979. 